\title{
ANALISIS DAN PERANCANGAN SISTEM EVALUASI PELATIHAN TENAGA KEPENDIDIKAN
}

\author{
Vina Zahrotun Kamila ${ }^{1)}$ dan Eko Subastian ${ }^{2)}$ \\ ${ }^{1}$ Program Studi Sistem Informasi, Fakultas Teknik, Universitas Mulawarman \\ ${ }^{2}$ Program Studi Pendidikan Komputer, Fakultas Keguruan dan Ilmu Pendidikan, Universitas Mulawarman \\ ${ }^{1}$ Jl. Sambaliung, Gunung Kelua, Samarinda, 75119 \\ ${ }^{1}$ Jl. Muara Pahu, Gunung Kelua, Samarinda, 75123 \\ E-mail : vinakamila@gmail.com ${ }^{1)}$, ekosebastian1989@gmail.com ${ }^{2)}$
}

\begin{abstract}
ABSTRAK
Penelitian ini merupakan penelitian pendahulu yang bertujuan untuk menganalisis dan merancang Sistem Evaluasi Pelatihan Tenaga Kependidikan sebelum diimplementasikan dan diuji di penelitian lanjut. Sistem Evaluasi Pelatihan Tenaga Kependidikan adalah sebuah sistem yang diajukan peneliti untuk melakukan kegiatan evaluasi pelatihan tenaga kependidikan untuk memudahkan dalam melakukan penilaian/ assessment kegiatan pelatihan berikutnya. Hasil penelitian ini diharapkan dapat memberikan manfaat untuk menjadi pertimbangan dalam mengimplementasikan rancangan sistem evaluasi tenaga kependidikan dan diaplikasikan di lingkungan Universitas Mulawarman. Metode basis aturan digunakan untuk mengklasifikasikan hasil evaluasi program pelatihan. Pelatihan yang akan dievaluasi adalah pelatihan tenaga kependidikan di lingkungan perguruan tinggi. Evaluasi pelatihan menggunakan dua sumber data evaluasi, yakni data kuesionerkuesioner kepuasan peserta dan data nilai pre-test, post-test dari peserta. Dengan aturan pada metode basis aturan yang ditetapkan oleh pengelola, proses evaluasi menghasilkan status pelatihan, yaitu kurang efektif, cukup efektif dan sangat efektif. Perancangan sistem berfokus pada sistem berbasis web (web-based). Perancangan sistem tidak sekedar berfokus pada pendaftaran dan pengumuman kelas pelatihan, melainkan berfokus pada evaluasi. Tahapan analisis dalam penelitian ini meliputi analisis kebutuhan fungsional dan non-fungsional dan digambarkan dengan use case diagram. Sedangkan tahap perancangan meliputi perancangan basis data dan perancangan antarmuka/ interface. Hasil dari penelitian ini menunjukkan rancangan Sistem Evaluasi Pelatihan Tenaga Kependidikan berbasis web sangat mungkin untuk diimplementasikan. Selanjutnya masih diperlukan penelitian lanjut untuk diuji penggunaannya nanti ketika diterapkan di lingkungan perguruan tinggi, khususnya di Universitas Mulawarman.
\end{abstract}

Kata Kunci: Sistem Informasi, Evaluasi Pelatihan, Web-Based, Rule-Based

\section{PENDAHULUAN}

Dalam bidang pendidikan, pelatihan tenaga kependidikan sudah tidaklah asing. Pelatihan-pelatihan ini diperlukan agar tenaga kependidikan (termasuk guru dan dosen) diperlukan untuk peningkatan pengetahuan dan kemampuan pendukung kegiatan belajar mengajar agar semakin mengikuti tren belajar peserta didik di era Teknologi Informasi yang semakin canggih. Namun, perlu dipertanyakan apakah pelatihan-pelatihan ini sudah efektif dilakukan. Dalam program/ kegiatan pendidikan dan pelatihan, evaluasi merupakan salah satu tahapan yang penting untuk dilakukan. Evaluasi kegiatan (program evaluasi) membantu mengidentifikasi apakah suatu kegiatan pelatihan telah mencapai sasaran yang ditargetkan oleh organisasi penyelenggara. Evaluasi kegiatan pelatihan terutama pelatihan untuk guru perlu di-setting secara khusus agar hasilnya objektif dan optimal (Christie and Fierro, 2012). Semakin cepat proses evaluasi dalam suatu kegiatan, semakin cepat pula akses informasi untuk dijadikan pertimbangan dalam merencanakan program pelatihan selanjutnya. Oleh karena itu, dibutuhkan suatu sistem yang dapat mendukung semua proses pada kegiatan pelatihan, seperti pendaftaran, pemberian sertifikat, evaluasi dan pelaporan dengan efektif dan efisien. Penggunaan teknologi web digunakan untuk mempermudah akses terhadap dukungan keputusan sehingga meningkatkan portabilitas dan fleksibilitas sistem.

Beberapa sistem informasi pelatihan telah dibangun, contohnya training registration system. Namun, sistem yang dibangun pada penelitian sebelumnya ini hanya mengakomodasi sistem registrasi (Rahimin, 2015). Sistem serupa juga pernah dibangun dengan evaluasi menggunakan model kirkpartick, tapi digunakan untuk pelatihan bidang kesehatan (Kamila and Subastian, 2016). Dalam beberapa penelitian lain terdapat juga rancangan sistem informasi pelatihan berbasis web yang dilakukan di berbagai bidang, seperti pada start-up penyedia berbagai layanan/ kelas pelatihan (Somya and Nathanael, 2019), balai latihan kerja (Fadhilah, Wahyudiono \& Waluyo, 2018) atau UPT pelatihan kerja (Nurhasan dkk., 2020), ataupun kursus setir mobil (Kristania, 2017). Akan tetapi dalam penelitian tersebut 
tidak berfokus pada evaluasi pelatihan yang mendukung keputusan manajemen untuk dilakukan assesment apakah pelatihan tersebut efektif dan dapat diadakan kembali di waktu mendatang.

Oleh karena itu, perlu dilakukan sebuah analisis dan perancangan untuk membangun suatu sistem informasi kegiatan pelatihan untuk tenaga kependidikan yang lebih berfokus pada evaluasi yang belum dilakukan pada penelitian-penelitian sebelumnya.

\section{RUANG LINGKUP}

Penelitian ini berfokus pada analisis dan perancangan sistem evaluasi pelatihan berbasis web dengan penerapan metode rule-based di dalamnya. Pelatihan-pelatihan yang dievaluasi dalam sistem merupakan pelatihan untuk tenaga kependidikan (termasuk guru dan dosen) di lingkungan Universitas Mulawarman.

Sistem ini nantinya akan diaplikasikan di lingkungan Universitas Mulawarman untuk mengukur/ mengevaluasi setiap pelatihan yang diikuti oleh staf, dosen maupun mahasiswa. Hasil evaluasi pelatihan akan dikembalikan kepada manajemen/ pembuat kebijakan untuk ditentukan apakah pelatihan serupa layak diikuti/ diadakan lagi di kemudian hari.

\section{BAHAN DAN METODE}

Bahan yang digunakan dalam penelitian adalah data primer dan sekunder dari metode kuesionerkuesioner dan data nilai peserta pelatihan. Metode yang digunakan dalam sistem adalah metode rule-based dalam sistem dan pengembangan sistem dengan teknologi web-based.

\subsection{Data Evaluasi Pelatihan}

Data evaluasi pelatihan berupa kuesionerkuesioner dan nilai yang didapatkan secara manual dan di inputkan ke dalam sistem. Berikut penjelasan mengenai metode pengumpulan data:

1. Metode KuesionerKuesioner

Evaluasi terhadap reaksi peserta pelatihan dapat dilakukan dengan mengukur kepuasan peserta. Program pelatihan dianggap efektif apabila peserta merasakan kepuasan pada pelaksanaan pelatihan. Kepuasan peserta pelatihan dapat diambil dari pandangan secara umum bagaimana opini terhadap pelaksanaan kegiatan atau dapat dibeda-bedakan dari beberapa aspek, misalnya materi yang diberikan, fasilitas yang tersedia, pengajar, media pembelajaran, ketepatan waktu, atau bahkan penyajian konsumsi selama kegiatan berlangsung. Pengukuran reaksi ini biasanya dilakukan dengan kuesioner yang diisi peserta.

\section{Metode Pre-Test dan Post-Test}

Evaluasi pembelajaran menggambarkan seberapa besar peningkatan pengetahuan/ kemampuan peserta setelah mengikuti kegiatan pelatihan. Terdapat tiga hal yang dapat pengajar/instruktur ajarkan dalam kegiatan pelatihan, yaitu pengetahuan, sikap maupun keterampilan (skill). Peserta pelatihan dikatakan telah belajar apabila pada dirinya telah mengalami perubahan sikap, perbaikan pengetahuan maupun peningkatan keterampilan.

Pembelajaran ini dapat diukur dengan nilai pre-test dan nilai post-test yang dimiliki peserta. Dengan nilai-nilai ini, pembelajaran dapat diukur apakah pengetahuan peserta mengalami peningkatan. Pengukuran peningkatan pengetahuan pada level dilakukan dengan mendapatkan gain score dari masing-masing peserta (Kirkpatrick, 2009). Perhitungan gain score dapat dilihat pada perhitungan (1).

gain score $(\%)=\frac{S_{\text {post }}-S_{\text {pre }}}{S_{\text {f.... }}-S_{\text {.... }}} \times 100(\%)$

Pada persamaan gain score (1), Spre merupakan skor/ nilai pre-test, Spost merupakan skor/ nilai post-test, dan Smax merupakan skor/ nilai maksimum.

\subsection{Metode Rule-Based}

Metode rule-based membentuk suatu aturan-aturan tertentu yang bertujuan membantu pengguna dalam menarik suatu kesimpulan. Metode ini mentransformasi aturan-aturan tersebut ke dalam bentuk pernyataan IFTHEN. Sistem rule based ini telah banyak digunakan untuk membantu dukungan keputusan dalam bidang kesehatan, jasa konsultan, manufaktur, pertanian dan pengajaran (Liao, 2005). Salah satu penerapan metode ini yang sekarang ini sering digunakan adalah untuk deteksi dini COVID-19 (Etikasari $d k k .$, 2020).

Penggunaan rule based untuk klasifikasi bertujuan untuk mengelompokkan suatu objek ke dalam kelaskelas tertentu dengan aturan yang telah ditentukan (Liu and Özsu, 2009). Penerapan i dalam sistem evaluasi pelatihan dapat dilihat pada Gambar 1.

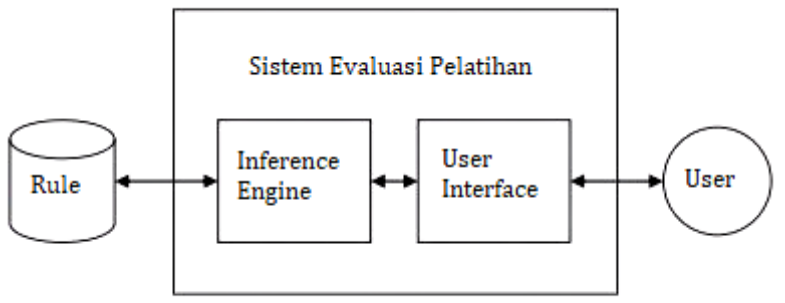

Gambar 1. Metode Rule-Based dalam Sistem

\subsection{Sistem Web-Based}

Sistem berbasis web memiliki peranan penting dalam mendukung keputusan. Jaringan internet, ekstra-net dan internet digunakan untuk menyajikan konten analisis dan solusi taktis dalam menyelesaikan masalah perencanaan produksi, distribusi, inventori. Penggunaan web telah meningkatkan aksesibilitas, ketepatan waktu, dan hasil 
dari pengambilan keputusan (Cohen, Kelly \& Medaglia, 2001). Dengan teknologi web, akses terhadap dukungan keputusan menjadi lebih mudah karena dapat diakses kapan pun dan di mana pun (Schewe and Thalheim, 2005).

Istilah sistem informasi berbasis web (web information system) menggambarkan sebuah sistem informasi dengan database yang direalisasikan dan didistribusikan melalui web dan diakses dengan aplikasi browser. Arsitektur sistem berbasis web yang digunakan pada sistem evaluasi tenaga kependidikan ditunjukkan pada Gambar 2.

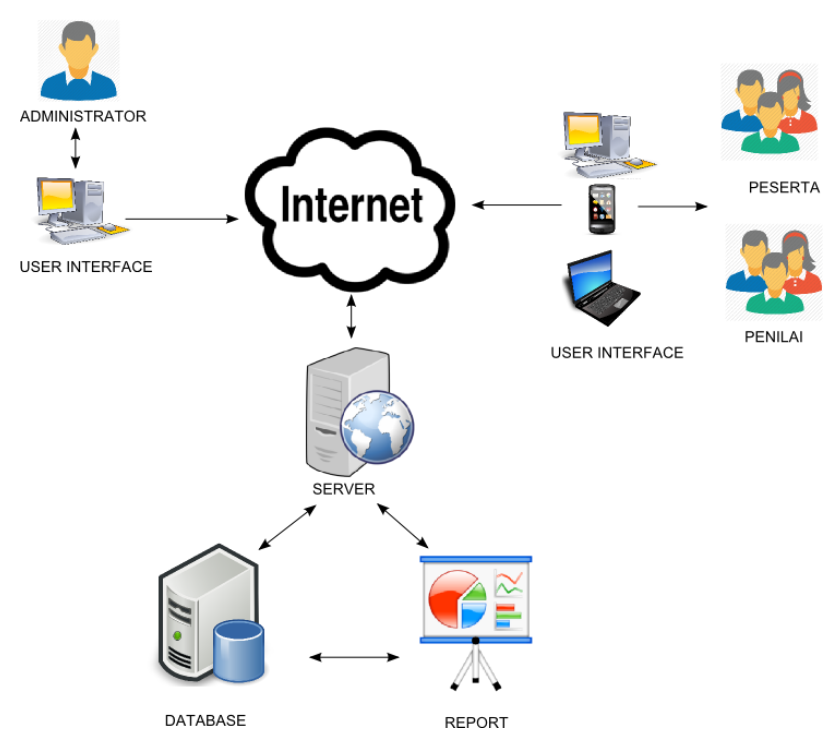

Gambar 2. Rancangan Arsitektur Sistem Web-Based

\section{PEMBAHASAN}

Dari hasil penelitian, tahapan analisis terdiri dari proses evaluasi, dan analisis kebutuhan sistem, sedangkan tahapan perancangan terdiri dari perancangan basis data dan perancangan antarmuka/ interface dari sistem.

Data yang diperlukan dalam proses ini antara lain adalah data peserta, data pelatihan dan data evaluasi. Data evaluasi diolah dengan metode rule-based. Hasil evaluasi berupa status pelatihan apakah kurang efektif, cukup efektif atau sangan efektif. Proses evaluasi yang diaplikasikan pada sistem digambar dalam flowchart pada Gambar 3.

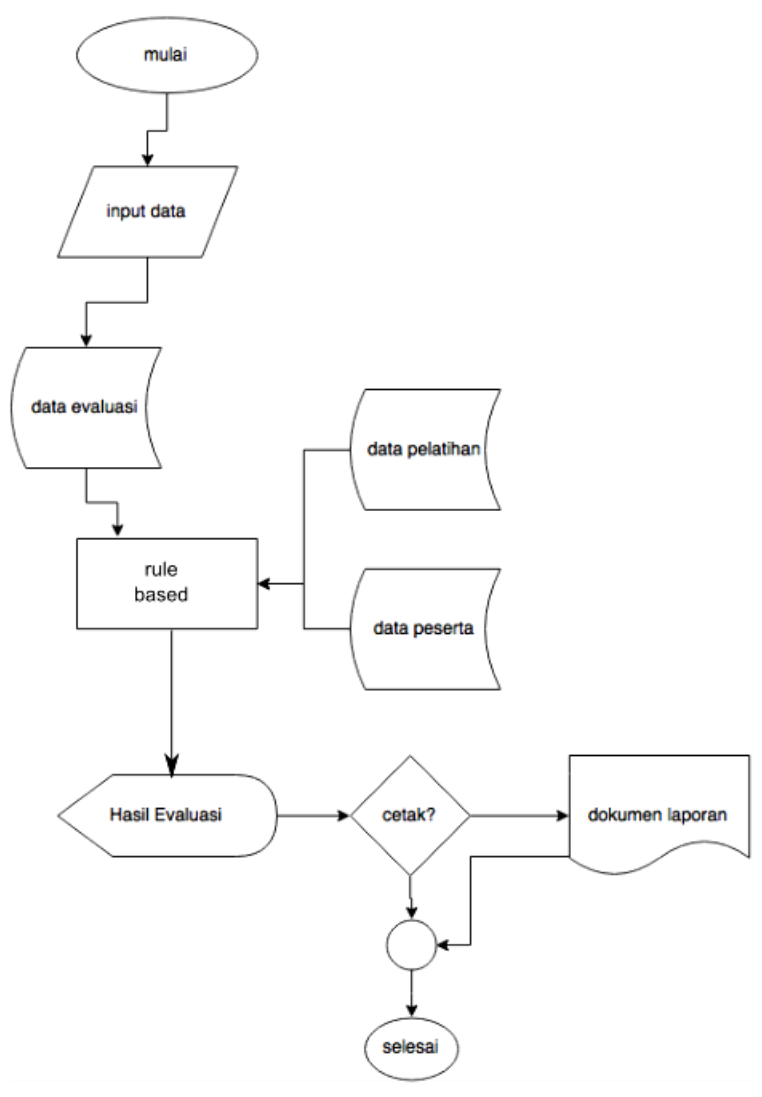

Gambar 3. Proses Evaluasi

Kebutuhan-kebutuhan (requirements) sistem dihimpun dari permasalahan yang telah dianalisis sebelumnya. Berdasarkan kebutuhan yang dihimpun dari user, kebutuhan sistem dibagi menjadi dua jenis, yaitu kebutuhan fungsional dan kebutuhan non fungsional. Kebutuhan-kebutuhan ini harus didefinisikan sebelum use case diagram dirancang.

Daftar kebutuhan fungsional terdapat pada Tabel 1. Tabel ini menunjukkan kebutuhan-kebutuhan (requirements) utama yang harus dipenuhi saat merancang sistem informasi kegiatan pelatihan.

Tabel 1. Kebutuhan Fungsional

\begin{tabular}{|c|c|}
\hline Kode & Deskripsi Kebutuhan Fungsional \\
\hline SR_F-001 & $\begin{array}{l}\text { User pengelola dapat meyimpan data } \\
\text { pelatihan }\end{array}$ \\
\hline SR_F-002 & $\begin{array}{c}\text { User pengelola dapat meyimpan data } \\
\text { peserta (calon peserta) }\end{array}$ \\
\hline SR_F-003 & $\begin{array}{l}\text { User pengelola dapat mendaftarkan peserta } \\
\text { pada suatu pelatihan, menyimpan data } \\
\text { pelaksanaan, data kehadiran dan data nilai } \\
\text { peserta pelatihan }\end{array}$ \\
\hline SR_F-004 & $\begin{array}{c}\text { User pengelola dapat menyimpan data } \\
\text { evaluasi (pertanyaan, aturan dan jawaban) }\end{array}$ \\
\hline
\end{tabular}


Tabel 1. Kebutuhan Fungsional (lanjutan)

\begin{tabular}{|c|c|}
\hline Kode & Deskripsi Kebutuhan Fungsional \\
\hline SR_F-005 & $\begin{array}{c}\text { User } \text { pengelola dapat melihat laporan } \\
\text { pelaksanaan pelatihan }\end{array}$ \\
\hline SR_F-006 & $\begin{array}{c}\text { User } \text { pengelola dapat melihat laporan } \\
\text { evaluasi pelatihan }\end{array}$ \\
\hline SR_F-007 & User pengelola dapat mencetak sertifikat \\
\hline SR_F-008 & $\begin{array}{c}\text { User } \text { peserta dapat menyimpan data } \\
\text { evaluasi (jawaban) }\end{array}$ \\
\hline SR_F-009 & $\begin{array}{c}\text { Semua } \text { user } \text { dapat melihat informasi } \\
\text { pelatihan }\end{array}$ \\
\hline
\end{tabular}

Daftar kebutuhan non fungsional ditunjukkan pada Tabel 2. Tabel ini menunjukkan kebutuhan-kebutuhan (requirement) tambahan sebagai penunjang untuk melengkapi tujuan utama dari pembangunan sistem.

Tabel 2. Kebutuhan Non Fungsional

\begin{tabular}{|c|c|}
\hline Kode & Deskripsi Kebutuhan Non Fungsional \\
\hline SR_NF-001 & Memiliki antarmuka user friendly \\
\hline \multicolumn{2}{|r|}{ Operational Requirement } \\
\hline SR_NF-002 & $\begin{array}{c}\text { Aplikasi client dapat terhubung ke server } \\
\text { dan mengakses web service melalui } \\
\text { protokol HTTP }\end{array}$ \\
\hline \multicolumn{2}{|r|}{ Performance Requirement } \\
\hline SR_NF-003 & $\begin{array}{c}\text { Sistem dapat terus berjalan selama tidak } \\
\text { terjadi kerusakan pada hardware dan } \\
\text { selama server aplikasi terkonfigurasi } \\
\text { dengan benar }\end{array}$ \\
\hline \multicolumn{2}{|r|}{ Security Requirement } \\
\hline SR_NF-004 & $\begin{array}{l}\text { Hanya admin yang telah terdaftar yang } \\
\text { dapat login ke sistem dan mengelola } \\
\text { database dan } \text { user } \\
\end{array}$ \\
\hline SR_NF-005 & $\begin{array}{l}\text { Admin tidak dapat menghapus data } \\
\text { tertentu melainkan hanya dapat } \\
\text { mengubah status keaktifan agar data yang } \\
\text { diakses konsisten dan tidak terjadi error } \\
\text { karena data tertentu yang berkaitan hilang }\end{array}$ \\
\hline \multicolumn{2}{|c|}{ Cultural and Political Requirement } \\
\hline SR_NF-006 & Memiliki antarmuka berbahasa Indonesia \\
\hline
\end{tabular}

Use case diagram untuk sistem evaluasi tenaga kependidikan dapat dilihat pada Gambar 4. Diagram ini menggambarkan interaksi user (sebagai actor) dengan aksi atau kumpulan fungsi (didalam use case diagram disebut dengan use case) pada sistem. Use case diagram yang dibuat kemudian menjadi landasan dari perancangan basis data dan antarmuka sistem.

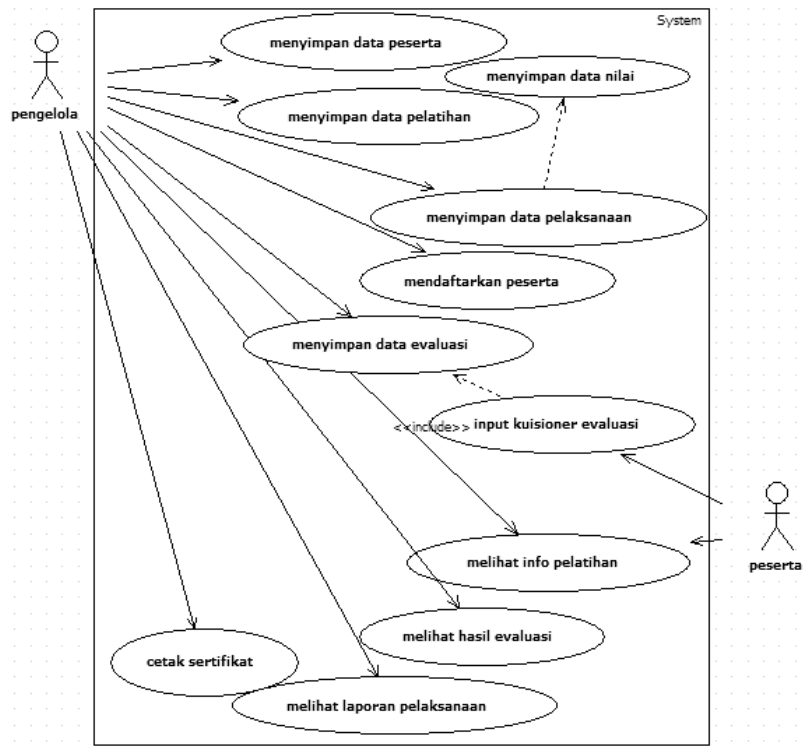

\section{Gambar 4. Use Case Diagram Sistem Evaluasi Pelatihan}

Maksud dari use case 'cetak sertifikat' adalah sertifikat dari pelatihan yang diadakan sendiri oleh perguruan tinggi. Sertifikat pelatihan dari luar secara opsional akan dapat di-upload ke dalam sistem ini.

Penjelasan mengenai setiap actor pada use case diagram sistem evaluasi tenaga kependidikan dapat dilihat pada Tabel 3.

Tabel 3. Deskripsi Actor pada Sistem Evaluasi Pelatihan

\begin{tabular}{|c|c|c|}
\hline Kode & Actor & Deskripsi \\
\hline $\begin{array}{l}\text { AC- } \\
001\end{array}$ & peserta & $\begin{array}{l}\text { user yang memiliki hak melihat } \\
\text { informasi umum pelatihan dan } \\
\text { hanya dapat menyimpan data } \\
\text { evaluasi dengan mengisi form-form } \\
\text { kuesioner evaluasi pelatihan }\end{array}$ \\
\hline $\begin{array}{l}\text { AC- } \\
002\end{array}$ & pengelola & $\begin{array}{l}\text { user yang memiliki hak akses } \\
\text { mengubah, dan menyimpan data } \\
\text { baru, dan melihat informasi- } \\
\text { informasi khusus seperti informasi } \\
\text { kehadiran seluruh peserta pada } \\
\text { semua pelatihan, laporan } \\
\text { pelaksanaan dan mencetak sertifikat. }\end{array}$ \\
\hline
\end{tabular}

Perancangan basis data didokumentasikan dengan entitiy relational diagram (ERD) dan rancangan tabeltabel basis data. ERD pada sistem informasi kegiatan pelatihan dapat ditunjukkan pada Gambar 5. 


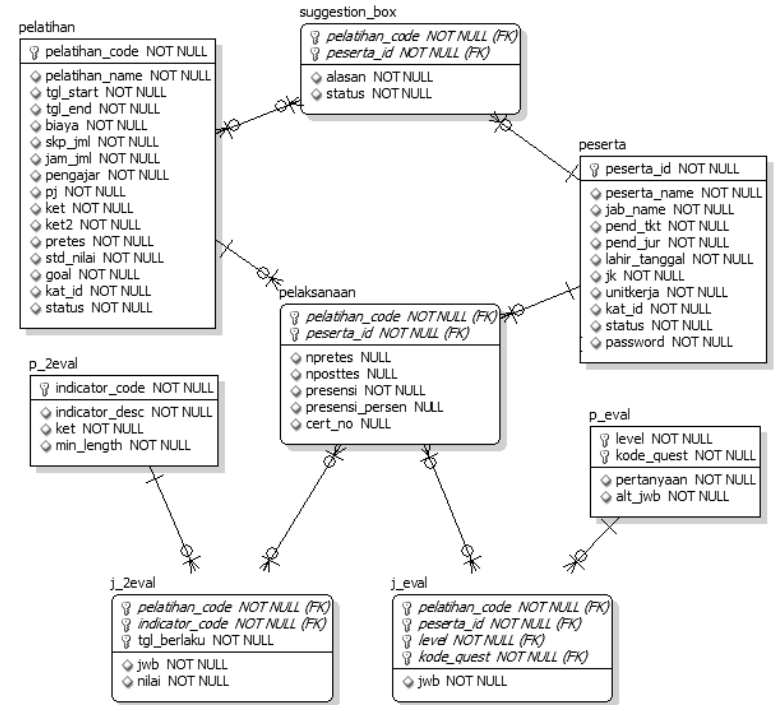

\section{Gambar 5. Entity Relationship Diagram Sistem Evaluasi Pelatihan}

Perancangan antarmuka merupakan tahapan di mana tampilan form input, tabel output dan tampilan lainnya dirancang. Berikut ini beberapa perancangan tampilantampilan utama dalam sistem. Gambar 6 merupakan rancangan form untuk mengubah (create/ update) datadata utama.

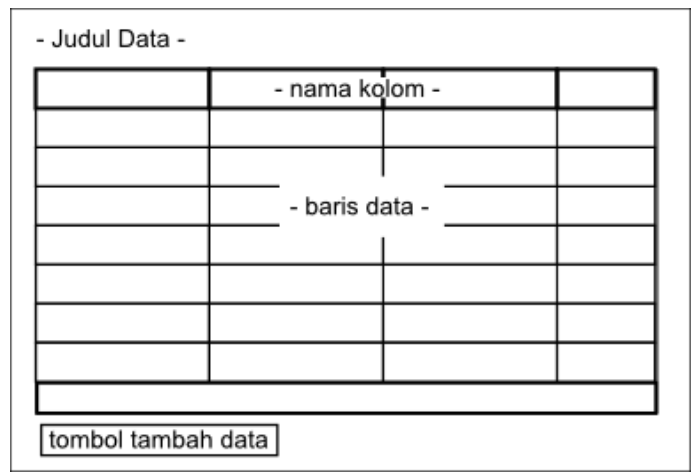

\section{Gambar 6. Rancangan Tampilan Form Tabel untuk Mengubah dan Menambah Data}

Tampilan Gambar 7 merupakan perancangan form untuk mengubah data yang sering di-update, seperti data pelatihan, peserta yang mengikuti pelatihan, presensi, nilai pre-test dan post-test dan sebagainya. Perancangan tampilan untuk input data dibedakan dari tampilan Gambar 6 agar memudahkan pengguna untuk menemukan form untuk input data yang dilakukan sehari-hari.

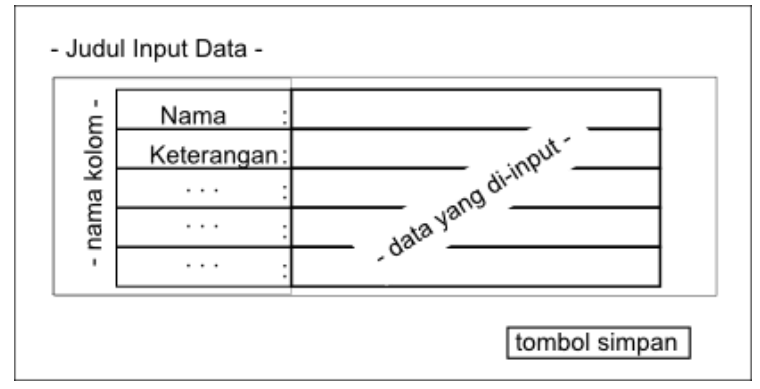

\section{Gambar 7. Rancangan Tampilan Form Tabel Untuk Input Data}

Perancangan tampilan untuk mengisi kuesioner ditunjukkan pada Gambar 8.

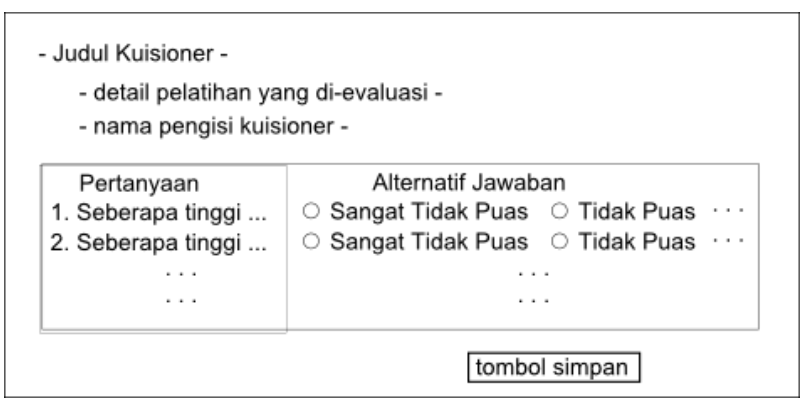

\section{Gambar 8. Rancangan Kuesioner Evaluasi}

Setelah kuesioner dan semua data evaluasi diisi dan diproses oleh sistem, maka akan ditampilkan tabel hasil dari evaluasi pelatihan yang ditunjukkan pada Gambar 9.

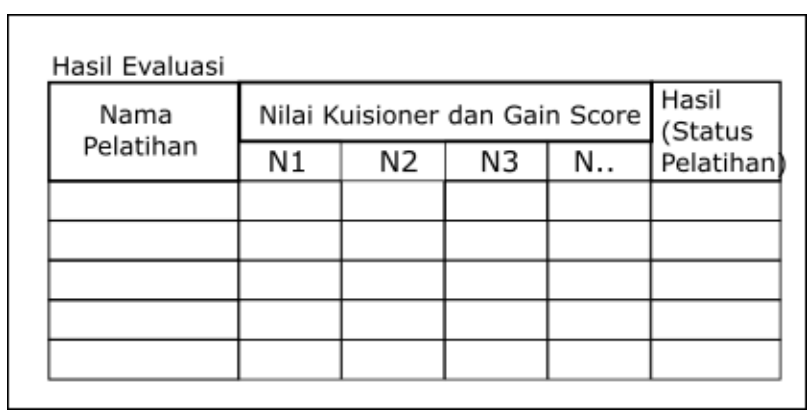

Gambar 9. Rancangan Tampilan Hasil Evaluasi

Aturan-aturan evaluasi akan diterapkan untuk penetapan status pelatihan pada laporan pelaksanaan pelatihan. Status pelatihan yang dihasilkan berupa pernyataan apakah suatu pelatihan sudah "sangat efektif", “cukup efektif" atau "kurang efektif". Status pelatihan ini yang nantinya digunakan sebagai dukungan keputusan pengelola dalam mengikuti/ mengadakan kegiatan pelatihan di masa mendatang. 


\section{KESIMPULAN}

Hasil penelitian menunjukkan bahwa analisis dan perancangan sistem evaluasi pendidikan untuk tenaga kependidikan berbasis web telah dilakukan. Metode rulebased dimasukkan dalam proses evaluasi untuk mengetahui efektivitas dari setiap pelatihan yang telah dilaksanakan/ diadakan, sehingga dapat digunakan oleh pihak manajemen/ pembuat kebijakan dalam menentukan apakah pelatihan dapat dilanjutkan di kemudian hari. Hasil dari penelitian ini sangat mungkin untuk dilanjutkan ke tahap implementasi dan diuji penggunaannya nanti ketika diterapkan di lingkungan perguruan tinggi, khususnya di Universitas Mulawarman.

\section{SARAN}

Untuk perbaikan dan pengembangan sistem pada penelitian selanjutnya, diharapkan sistem ini masih harus diimplementasikan dan diujikan di lapangan agar dapat dilihat bagaimana efektivitas dan efisiensinya ketika diterapkan secara utuh. Sedangkan untuk penerapan di bidang lain perlu dilakukan, karena karakteristik pelatihan berbeda-beda dan sangat bervariasi, misalkan pelatihan di bidang teknik yang membutuhkan praktik dengan alat, ataupun bidang lainnya.

\section{DAFTAR PUSTAKA}

Christie, C. A. and Fierro, L. A. (2012) 'Evaluation policy to implementation: An evaluation of scientifically based research in practice', Studies in Educational Evaluation, 38(2), pp. 65-72. doi: https://doi.org/10.1016/j.stueduc.2012.05.003.

Cohen, M.-D., Kelly, C. B. and Medaglia, A. L. (2001) 'Decision support with Web-enabled software', Interfaces, 31(2), pp. 109-129.

Etikasari, B. $d k k$. (2020) 'Sistem Informasi Deteksi Dini Covid-19', Jurnal Teknik Elektro Dan KOmputer, 9(2), pp. 101-108.

Fadhilah, K. N., Wahyudiono, S. and Waluyo, S. (2018) 'Sistem Informasi Pelatihan di Balai Latihan Kerja
Kabupaten Magelang', JURNAL TRANSFORMASI, 13(2).

Kamila, V. Z. and Subastian, E. (2016) 'Sistem Informasi Evaluasi Pelatihan Bidang Kesehatan Berbasis Model Evaluasi Kirkpatrick', In Science And Engineering National Seminar 2 (Sens 2), Universitas Pgri Semarang, pp. 178-187.

Kirkpatrick, D. L. (2009) Evaluating Training Programs: The Four Levels. ReadHowYouWant.com, Limited. Available at: https://books.google.co.id/books?id=4rYs1 wnyUHU C.

Kristania, Y. M. (2017) 'Sistem Informasi Pelatihan Mobil Pada Citra Indotech Jaya Purwokerto Berbasis Desktop', Jurnal Khatulistiwa Informatika, $5(1)$.

Liao, S.-H. (2005) 'Expert system methodologies and applications - a decade review from 1995 to 2004', Expert systems with applications, 28(1), pp. 93-103.

Liu, L. and Özsu, M. T. (2009) Encyclopedia of database systems. Springer New York, NY, USA:

Nurhasan, U. dkk. (2020) 'Implementasi Metode MVC untuk Pembangunan Sistem Informasi Pelatihan Kerja: Studi Kasus UPT Pelatihan Kerja Singosari', Jurnal Eksplora Informatika, 10(1), pp. 20-31.

Rahimin, D. (2015) 'Training Registration System: Design Concept and Benefits', Technology, 1(1), pp. 23-28.

Schewe, K.-D. and Thalheim, B. (2005) 'Conceptual modelling of web information systems', Data \& knowledge engineering, 54(2), pp. 147-188.

Somya, R. and Nathanael, T. M. E. (2019) 'Pengembangan Sistem Informasi Pelatihan Berbasis Web Menggunakan Teknologi Web Service Dan Framework Laravel', Jurnal Techno Nusa Mandiri, 16(1), pp. 51-58. 